\title{
Thermomechanical interactions between crustal magma chambers in complex tectonic environments: insights from Eastern Turkey
}

\author{
Özgür Karaoğlu ${ }^{*}$, Özgür Bayer², Metin Bilgehan Turgay², John Browning ${ }^{3,4}$ \\ ${ }^{1}$ Department of Geological Engineering, Eskişehir Osmangazi University, , 26040, Eskişehir, \\ Turkey \\ ${ }^{2}$ Department of Mechanical Engineering, Middle East Technical University, Çankaya, Ankara, \\ 06800, Turkey \\ ${ }^{3}$ Department of Mining Engineering and Department of Structural and Geotechnical Engineering, \\ Pontificia Universidad Católica de Chile, Santiago, Chile \\ ${ }^{4}$ Centro de Excelencia en Geotermia de los Andes (CEGA), Chile
}

Correspondence and requests for materials should be addressed to Ö.K. (email: ozgur.karaoglu@deu.edu.tr; cougarforever@gmail.com)

\begin{abstract}
Crustal segments, such as those in Eastern Turkey, which host magma chambers, volcanoes, and fault zones, experience complex stresses generated through interactions between regional tectonic loading, magmatic pressure, and geothermal dynamics. Here we model these competing loading mechanisms and examine their effects on generating stresses in a complex crustal segment which has been subjected to orogenesis and hosted voluminous magma discharge. This simulatedregion hosts several volcanoes, thermal fields and has experienced complex tectonic deformation which manifests as crustal faults. We present a suite of purely thermal models to show the temperature distribution within the crust assuming an arrangement of crustal magma chambers and a realistic geothermal gradient. We also present a suite of linear elastic mechanical models to investigate the effect of magma pressure and regional tectonic loading in the absence of temperature variations using different arrangements of magma chambers and faults. Finally, we present coupled linear elastic thermomechanical models that highlight the influence of temperature
\end{abstract}


on the distribution of both crustal stresses and deformation using the same complex geometries. Results show that thermal stresses generate two competing consequences, 1) they increase the level of shear stress around the magma chambers, potentially leading to fault nucleation or reactivation, and 2) they partially act to suppress the level of tensile stress originally generated both by magma pressure and tectonic loading. This implies that for any magmatic recharge event, which increases the internal magma chamber pressure, the contribution of temperature increase in the surrounding host rocks must also be taken into account when considering the distribution, magnitude and type of stresses around magma chambers in such crustal environments. 


\section{Introduction}

(n)

The way in magma chambers behave mechanically in different tectonic environments and under different crustal deformation conditions remains poorly constrained, particularly when considering the crustal response to thermomechanical loading (Mogi, 1958; Marsh, 1989; Gudmundsson, 2012). Variations in thermomechanical crustal loading arise from the emplacement of hot magmatic fluids but will be complicated in regions of large differential stress, such as active fault zones (i.e., Fitton et al., 1991). In terms of regional thermomechanical behaviour, convergent plate margins are among the most complex tectonic and temperature environments on Earth. In principle, the collision of two continental plates, which results in subduction, generates hybrid magmas through melting of the subducted-plate, which is in turn structurally controlled by compressional tectonics. However, understanding of some volcanic provinces linked to subduction-related or post-orogenesis is more complex because of the retreat and the geometry of the subducted-slab, and the thermomechanical differentiation between crustal materials on Earth (Gorczyk et al., 2007; Paterson et al., 2011). In order to better understand the origin of magmas, the propagation of magma through the crust, and the ensuing crustal deformation, models that take account of both the thermal and mechanical properties of the crustal segments that host magma are needed (i.e., Cloos, 1985; Lagabrielle et al., 2000; Gorczyk et al., 2007).

To address both of these issues, we conducted a numerical study to compare the elastic effects of both mechanical and thermal loading on a complex crustal segment based on a region of Eastern Turkey (i.e., Karaoğlu et al., 2017, 2018). We present a suite of numerical models that simulate the temperature field of the simulated region. All of the combined heat distribution and stress components presented are designed to further our understanding of how changes in crustal temperature influence elastic deformation and hence generate crustal stresses and rock fracture in 
the regionally complex thermodynamic setting of the Karlıova Triple Junction (KTJ) in Eastern Turkey.

The main goal of this study is, hence, to better understand the nature of elastic thermomechanical interactions between crustal magma chambers by taking account of both the thermal and mechanical stress distributions surrounding such magma bodies (i.e., Hickey et al., 2016; Townsend et al., 2019). Understanding crustal heat distribution is important in fully characterising thermomechanical models of magmatic and geothermal systems (Jaupart et al., 1998). The temperature distribution around crustal segments that host volcanoes and magmatic systems influence the movement of fluids, through convection, and hence partly controls the development of geothermal systems and the deposition of ore minerals (Eldursi et al., 2009). As such, thermomechanical models have been used to understand the nucleation and development of faults generating large scale volcanic collapse features such as calderas (Burov \& Guillou-Frottier, 1999). However, the effect of elastic thermomechanical stressing on stress concentrations around fault zones have not received sufficient attention.

\section{Geological and tectonic settings}

The geodynamic history of eastern Turkey is dominated by the convergence of the African, Arabian and Eurasian plates since the early Mesozoic (Dewey et al., 1986; Şengör et al., 1985). Following crustal shortening resulting from a NNE-SSW convergence between the Arabian and Eurasian plates, the westward extrusion of the Anatolian plate was accommodated by two conjugate leftlateral EAFZ (East Anatolian Fault Zone) and right-lateral transform faults NAFZ (North Anatolian Fault Zone) nearly 6 Ma (Şengör et al., 1985; Karaoğlu et al., 2017, Fig. 1 a,b). The migration of the Anatolian plate caused substantial deformation around the Karlova Triple Junction (KTJ) 
which in turn promoted and accommodated the initiation of volcanism in the province (Fig. 1c). Crustal complexities around the KTJ have been shown to significantly control the geometry of magma emplacement and propagation (Karaoğlu et al., 2016, 2018). The initiation of magmatism is closely associated with incremental and complex deformation of the crust that hosts the KTJ. Karaoğlu et al. (2016) presented a relationship between this crustal complexity and magmatic dike geometries. According to Karaoğlu et al. (2016, 2018), dikes propagate through a highly heterogeneous crust which hosts both inclined-layers or variable stiffness and multiple crustal faults.

Widespread volcanic activity around the KTJ, initiated since the late Miocene, has been subdivided into three chemically distinct groups as follows: 1) Early Phase (Solhan volcanism; 7.3-4.4 Ma), characterised with alkali basalt to trachyte lava flows and pyroclastic successions; 2) Middle Phase (Turnadağ and Varto volcanism; 3.6-2.6 Ma), with emplacement of products of basalts, trachytes, dacites and rhyolites, and 3) Late Phase (Özenç volcanism; 2.6-0.5 Ma), mostly erupted of products of alkali basaltic, hawaiitic and mugearitic lavas and dykes (Fig. 1c; Karaoğlu et al., 2020).

To estimate magma chamber depths and sizes around the KTJ, Karaoğlu et al. (2018) used an analytical method, based on the aspect ratio (length/thickness) of dikes. They showed that the depths of the magma chambers feeding the observed dikes were between 2 and $4 \mathrm{~km}$ at Turnadag and between 2 to $5 \mathrm{~km}$ at Varto. Both of these complexes were subjected in transtensional tectonics. Whereas the depth of the chambers at the Özenç complex ranged between 22 to $27 \mathrm{~km}$ which was instead formed in a dominantly convergent tectonic setting. Teleseismic $P$-wave tomograms confirm the existence of magma stocks at depths between 3 and $10 \mathrm{~km}$ below the both Turnadag and Varto volcanoes. The tomograms also indicate a deep magma reservoir residing between 15 $\mathrm{km}$ and $30 \mathrm{~km}$ in the Özenç region (Karaoğlu et al., 2018). 
Wide-spread Plio-Quaternary volcanism (Jaupart et al., 1998; Aydin et al., 2005) and segmentation of the lithosphere (Eldursi et al., 2009; Parks et al., 2015) has produced a higher-than-average geothermal gradient in Eastern Turkey (Bektaş et al., 2007; Aydin et al., 2005; Karaoğlu et al., 2019). Curie point depths indicate the deepest point of magnetic sources (approximately $580{ }^{\circ} \mathrm{C}$ for magnetite at atmospheric pressure) and can hence be used to reflect the geothermal gradient. The Curie point depth map of Turkey, constructed from a spectral interpretation of magnetic anomaly data, shows that the magnetic thickness of the region varies from 13 to $23 \mathrm{~km}$ (Deb, 2006). This map also indicates that the Curie point depth is nearly $18-20 \mathrm{~km}$ in the Karlova region (Bektaş et al., 2007; Aydin et al., 2005). The geothermal gradient of the region can then be calculated by dividing $580{ }^{\circ} \mathrm{C}$ by the Curie point depth and hence provides a temperature gradient of approximately $30^{\circ} \mathrm{C}$ per $\mathrm{km}$.

\section{Methods}

\subsection{Numerical models}

All of the Finite Element numerical model geometries, created in COMSOL Multiphysics 5.5 (Tabatabaian, 2014), were based on field observations and published papers on the KTJ (Thompson \& Connolly, 1995; Aydin et al., 2005; Topuz et al., 2017). The models are all two dimensionally symmetric and the magma chambers are considered as cavities or holes with an applied internal excess pressure $\left(P_{e}\right)$ and temperature $\left(T_{e}\right)$ (e.g., Gudmundsson, 2011; Gerbault, 2012; Karaoğlu et al., 2016). All models are based upon an E-W striking profile, through the Karlova region, that encompasses volcanic provinces and fault zones (Fig. 2). We assume ellipsoidal, or sill-like, magmatic geometries, typical of well-documented magma chambers around the world (e.g., Gudmundsson, 2012; Chestler \& Grosfils, 2013; Le Corvec et al., 2013; Caricchi et al., 2014). Although near-surface stress fields may be affected by topography, the primary focus of the presented models is on the stress differences caused by mechanical loading on vertical 
sideboundaries and thermal variations applied to the magma chambers. Therefore we decided to use a flat topography in all models. The models are created as two main geometries both of which are hosted in a crustal domain segment of $60 \mathrm{~km}$ in length and $30 \mathrm{~km}$ in depth. The first model named as two-magma-chmanber model, includes two shallow magma chambers with their roofs at depths of $8 \mathrm{~km}$ and they are both $9 \mathrm{~km}$ in length and $2 \mathrm{~km}$ in thickness (Fig. 2). The second model (three-magma-chamber model) also encompasses these shallow magma chambers but with an additional deeper magma reservoir located at $15 \mathrm{~km}$ below the crustal surface. The deeper reservoir is $24 \mathrm{~km}$ in length and $3 \mathrm{~km}$ in thickness. Both models also host a series of faults which are simulated as zones of softer, or more compliant rocks. The magma chamber and fault locations are based on the results of Karaoğlu et al. (2016). The models are heterogeneous in that they also combine 14 different horizontal mechanical layers, or stratigraphic units, which are again based on geological observations (e.g., Karaoğlu et al., 2016) (Supplementary Figure S1). The upper crust is assumed to be mostly made up of limestone, metamorphic rocks, massive gabbro and sandstones with estimated laboratory densities ranging 2000 to $3100 \mathrm{~kg} \mathrm{~m}^{-3}$ (e.g., Gudmundsson, 2011). The Young's modulus (E) of layers in Fig. 2 alters within a reasonable range for rock units at corresponding depths with values between $20 \mathrm{GPa}$ and $50 \mathrm{GPa}$. . We use constant typical values of Poisson's ratio (v) of 0.25 (e.g., Gudmundsson, 2012) as $v$ does not vary significantly for these rock layers. The fault zones, the most compliant units, are represented by sub-vertical polygons (Efault $)$ in Figure 2. The Young's modulus and Poisson's ratio values for the fault zones are defined as $0.1 \mathrm{GPa}$ and 0.33 , respectively, as derived from active fault zones elsewhere (Gaffney et al., 2007; Gudmundsson, 2011; Karaoğlu et al., 2018).

The thermal properties of each layer of country rocks are listed in the Supplementary Table 1. We use $k\left[\mathrm{~W} /\left(\mathrm{m}^{*} \mathrm{~K}\right)\right]$ for thermal conductivity in the range of 0.45 and $0.92, C_{p}$ for specific heat $\left[\mathrm{J} /\left(\mathrm{kg}^{*} \mathrm{~K}\right)\right]$ in the calculation of transient thermal conditions (response of a rock body to a transient heat source or sink) which varies from 690 to 990 , and $\alpha$ is the coefficient of thermal expansion 
$125[1 / \mathrm{K}]$ in the range of $1.6 \times 10^{-5}$ and $6 \times 10^{-6}$ for each rock unit. The lower thermal expansion values are linked to the thermal and mechanical properties of lithological units consisting unconsolidated mudstone and sandstone presented as layer E2 in the Supplementary Table 1. It is important to note that we are attempting to characterize the precise nature of each units mechanical properties but simply consider the resulting stress effects of different units. Hence the values used are typical of crustal rocks but not precisely represent the values in the studied region as there is virtually no information on such properties in these crustal rocks.

\subsection{Governing equations for the model set ups}

When we neglect radiative heat transfer, a steady form of the equation solved in the Heat Transfer in Solids interface of COMSOL can be used and it becomes:

$\rho C_{p} u \cdot \nabla T+\nabla \cdot q=q_{0}+Q_{t e d}+Q$

where $\rho$ is density, $C_{p}$ is specific heat at constant stress, $T$ is absolute temperature, $u$ is a velocity vector of translational motion, $Q$ represents heat transfer from other sources, in this case from the shallow magma chambers and deeper magma reservoir, and $q$ is heat flux by conduction and defined as;

$q=-k \nabla T$

where; $k$ is thermal conductivity, as mentioned before. $Q_{t e d}$ is a thermoelastic dampening that accounts for thermoelastic effects in solids and is only relevant when the heat transfer is coupled to the solid mechanics and is calculated as:

$Q_{\text {ted }}=-\alpha T: \frac{d S}{d t}$

where; as stated, $\alpha$ is the coefficient of thermal expansion, and $S$ is the second Piola-Kirchhoff stress tensor.

In the "Solid Mechanics" interface of COMSOL the steady form of the equation of motion for linear elastic material is solved as follows:

$0=\nabla \cdot S+F_{v}$ 
$S=S_{a d}+C: \varepsilon_{e l}$

151

152

153

154

155

156

157

158

159

160

161

162

163

164

165

166

167

168

169

170

171

172

173

$\varepsilon_{e l}=\varepsilon-\varepsilon_{\text {inel }}$

$\varepsilon=\frac{1}{2}\left[(\nabla u)^{T}+\nabla u\right]$ defined as;

$\varepsilon_{t h}=\alpha\left(T-T_{\text {ref }}\right)$

$S_{a d}=S_{0}+S_{\text {ext }}+S_{q}$

$\varepsilon_{\text {inel }}=\varepsilon_{0}+\varepsilon_{\text {ext }}+\varepsilon_{t h}+\varepsilon_{h s}+\varepsilon_{p l}+\varepsilon_{c r}+\varepsilon_{v p}$

In these equations $C$ is the constitutive tensor which is a function of Young's modulus $(E)$ and Poisson's ratio $(v), F_{v}$ is the volume force vector, $\varepsilon$ is a strain tensor, and $u$ is the displacement field, $\varepsilon_{p l}$ is a plastic strain, $\varepsilon_{c r}$ is creep strain, $\varepsilon_{e l}$ is elastic strain, $\varepsilon_{i n e l}$ is inelastic strain, $\varepsilon_{0}$ is initial strain, $\varepsilon_{e x}$ is the external strain, $\varepsilon_{h s}$ is a hygroscopic strain, $\varepsilon_{v p}$ is a viscoplastic strain, and finally, $\varepsilon_{t h}$ is thermal strain which is a function of both temperature and thermal expansion coefficient,

\subsection{Boundary Conditions and Parameters}

Only the thermal boundary conditions are necessary to solve the governing equations in heat transfer simulations; whereas, for the coupled simulations of heat transfer and solid mechanics we require both mechanical and thermal boundary conditions.

For the heat transfer simulations; the temperature of the upper horizontal boundary (the earth's surface) of the computational domain $\left(T_{u p}\right)$ is set to $0{ }^{\circ} \mathrm{C}$. The wall temperatures of the two shallow magma chambers $\left(T_{e 1}, T_{e 2}, T_{e 3}, T_{e 4}, T_{e 5}, T_{e 6}\right)$ are both set to $300{ }^{\circ} \mathrm{C}, 600{ }^{\circ} \mathrm{C}$ or $900{ }^{\circ} \mathrm{C}$ while the other larger and deeper magma reservoir wall temperature $\left(T_{e 7}, T_{e 8}, T_{e 9}\right)$ is set to $600{ }^{\circ} \mathrm{C}, 900{ }^{\circ} \mathrm{C}$ or $1200{ }^{\circ} \mathrm{C}$. Two additional temperature boundary conditions are used for the left side, right side, and lower boundary of the computational domain. In all model cases, as previously performed in measurements of Jaupart et al. (1998) and Eldursi et al. (2009), the temperature of the vertical sides 
is defined as a function of depth in which the temperature increases $30^{\circ} \mathrm{C}$ for every $1 \mathrm{~km}$ of depth increment, and given in Equation (11) below, reaching a maximum of $900{ }^{\circ} \mathrm{C}$ at the lower horizontal boundary.

$T_{b}(y)\left[{ }^{\circ} \mathrm{C}\right]=30 y[\mathrm{~km}]$

For the solid mechanics part of the simulations; the upper horizontal boundary of the computational domain is defined as a free surface, i.e., the interaction with an area that cannot accommodate shear stress. For the lower horizontal boundary, zero shear stress and zero normal strain is set. On the other hand; five different mechanical boundary loading conditions are considered to simulate compression and extension at the left and right vertical sides of the computational domain, namely $-10,-5 \mathrm{MPa}$ (simulating extension); 0 and $,+5,+10 \mathrm{MPa}$ (simulating compression). Excess pressure $\left(P_{e 1}, P_{e 2}, P_{e 3}\right)$ of $5 \mathrm{MPa}$ is applied at the boundaries of all magma chambers.

The models assume two-dimensional plane-strain conditions . Hence, the magma chambers are approached as cavities with an infinite in plane depth. We do not attempt to upscale the results to three-dimensions here.

Depending on the model (two-magma-chamber or three-magma-chamber), appropriate boundary conditions summarized are used, and every combination of these boundary conditions are considered. Boundary conditions are also indicated in the Supplementary Table 2.

\subsection{Model Mesh}

Throughout this study, we implemented COMSOL's predefined extremely fine mesh setting with triangular quadratic elements which were used for all the model runs. This extremely fine mesh setting yields a maximum element size of $0.6 \mathrm{~km}$ and a minimum element size of $0.001 \mathrm{~km}$, and 
an average element quality of 0.87 . As such, the total number of elements used in the two magma chamber and three magma chamber geometry models were 63,575 and 68,771 , respectively.

\section{Results}

Three different types of simulation, for both the two-magma-chamber and three-magma-chamber configurations, were executed in order to analyse and compare the changes in thermal and mechanical stress with depth around the magma chambers. The results are presented in Figures 38. The characteristics of these simulations are as follows: (1) Thermal simulation without mechanical coupling (Heat transfer only simulation - Fig. 3), in which thermal boundary conditions provided in Supplementary Table 2 are valid and there is no mechanical stress applied or calculated. (2) Purely mechanical simulation that reveals the elastic deformation associated only with magmatic overpressure and regional extension or compression (Figure 4). (3) Coupled thermomechanical stress simulation for both two-magma-chamber (Fig. 5) and three-magmachamber (Fig. 6-8) configurations. In the corresponding coupled simulations, stresses are generated by both thermal expansion of the rocks surrounding the magma chambers and internal magma pressure of $5 \mathrm{MPa}$. In all aforementioned three different types of simulation, the temperature of the boundaries of the shallow magma chambers is set to $300{ }^{\circ} \mathrm{C}, 600{ }^{\circ} \mathrm{C}$, or $900{ }^{\circ} \mathrm{C}$, the temperature of the boundariy of the deeper magma reservoir is defined as $600{ }^{\circ} \mathrm{C}, 900{ }^{\circ} \mathrm{C}$, and $1200^{\circ} \mathrm{C}$.

\subsection{Heat transfer only simulation}

In this suite of first simulations, we explored the temperature distribution within the domain depending on the magma chambers' temperature values and arrangement. There is no mechanical coupling in both two-magma-chamber or three-magma-chamber models and only a temperature field output is generated. In order to visualize how high the temperature could be, the corresponding 
temperature profile results, within the domain, are presented for both models considering internal temperatures of $900^{\circ} \mathrm{C}$ in the shallow magma chambers and $1200^{\circ} \mathrm{C}$ in the deeper magma reservoir, as displayed in Figure 3. As such, the temperature field output gives a temperature differential, or change in temperature which is essential for understanding thermal stress.. In all runs we plot the temperature field as a 2D surface and as curves of temperature vs distance along the profile at different depths representing the earth's surface, and at $0.1 \mathrm{~km}, 0.5 \mathrm{~km}, 1 \mathrm{~km}, 4 \mathrm{~km}$ and $9 \mathrm{~km}$ depth, respectively (Sections 1-6 in Fig.2).

As expected, heat is symmetrically distributed around the two shallow magma chambers with peaks in the central sections above their respective roofs in two-magma-chamber model simulation. Temperature decreases with distance from the two chambers.. However, the central part of the domain remains with an elevated temperature of a few hundred degrees. Near the surface the temperature becomes elevated by around $10^{\circ} \mathrm{C}$, particularly in the regions directly above the magma chambers (Figures 3a, 3b and 3c). It should be noted that despite the different thermal expansion properties of the fault zones, none affect the diffusion of the heat. This fact is obvious because, the heat transfer only simulation does not take thermomechanical interactions into account and hence none of the rock units deform.

The effect of adding an additional, much larger and much hotter magma body results in an asymmetry in the temperature field (Figures $3 \mathrm{~d}, 3 \mathrm{e}$ and $3 \mathrm{f}$ ). The right part of the domain hosting the larger and deeper magma reservoir has a higher temperature than the left part.. The entire crustal segment becomes hotter and the region of increased temperature is much larger. The temperature observed just below the earth surface also increases by around $10^{\circ} \mathrm{C}$ as in the two-magma-chamber model (Figures $3 \mathrm{~d}$ and $3 \mathrm{e}$ ). The fault zones, again, have no effect on the temperature distribution.

\subsection{Purely mechanical simulation}


In the second suite of simulations, the crustal segment is mechanically loaded by applying an internal overpressure in the magma chambers and an extensional or compressional load at the vertical boundaries is analysed for the three-magma-chamber model (Fig. 4). The extentional or compressional load is applied by assigning a $-10 \mathrm{MPa}$ or $+10 \mathrm{MPa}$ pressure vertical side loading condition. Analyses are presented in terms of the resulting amounts of minimum principal compressive stress $\left(\sigma_{3}\right)$ and von Mises shear stress $(\tau)$.

Numerical analyses' results show that both $\sigma_{3}$, and $\tau$, predominantly concentrate at the lateral margins of each magma chamber and at the earth's surface above the magma chambers when only an internal magmatic pressure is applied (Figures $4 \mathrm{a}$ and $4 \mathrm{e}$ ). When a regional extension is applied, the stress patterns remain with a similar behaviour but the absolute values of stress increase (Figures $4 \mathrm{~b}$ and $4 \mathrm{f}$ ). Shear stress concentrates above the magma chambers and localises or dissipates at fault contacts (Figure 4f). Regional compression has the result of altering the orientation but not the magnitude of the $\sigma_{3}$ (Figure $4 \mathrm{c}$ and $4 \mathrm{~g}$ ). However, some shear stress concentration above right-shallow magma chamber is notable (Fig. 4g).

When all stress values are evaluated together, it is revealed that the $\sigma_{3}$ values in the extensional regional stress environment are around $5 \mathrm{MPa}$ more than in the compressional case. However, it is also observed that $\tau$ magnitudes have the same values under both extensional and compressional regional loading (Figure 4d-h).

\subsection{Coupled thermomechanical simulation}

In final suite of simulations, we investigated the effect of coupled thermal and mechanical loading and the resulting crustal stress response in both the two and three-magma-chamber configurations, considering all of the magma chamber temperature combinations and vertical side boundary 
mechanical loading conditions, as presented in Supplementary Table 2. The stress distributions resulting from the two magma chamber configuration are given in Figure 5 for each of the three temperatures tested $\left(300{ }^{\circ} \mathrm{C} ; 600^{\circ} \mathrm{C}\right.$ and $\left.900{ }^{\circ} \mathrm{C}\right)$, and in the more complex (three-magma-chamber configuration, with/without additional boundary loading) are given in Figures 6, 7 and 8 for the range of temperatures described earlier. The results of the analyses are again presented in terms of temperature and the distribution of $\sigma_{3}$ and $\tau$.

The difference in the coupled thermomechanical simulations, with respect to the previous purely mechanical models, is that the temperature now exerts a mechanical response in the form of thermal expansion and hence thermal expansion induced stressing. The temperature profile generated in these thermomechanical simulations is essentially identical to that described in Section 4.1.

The effect of the heated magma chambers induces a crustal stress field which is most notable in the regions of largest temperature difference directly above the centre and directly below the centre of the two shallow magma chambers (Fig. 5). As the layers hosting the chambers are heterogeneous they experience different levels of stress distribution. This crustal heterogeneity is exacerbated where there are compliant crustal segments which concentrate or dissipate stresses. Cross-sections at various depths show a highly heterogeneous profile of crustal stresses, both in terms of $\sigma_{3}$ (Fig. 5a,b,c) and $\tau$ (Fig. 5.e,f,g). For example, $\tau$ is highest directly above and below the two shallow magma chambers, whereas both $\tau$ and $\sigma_{3}$ increase locally at the margins of the faults. Generally, we note that the $\sigma_{3}$ decreases at the magma chamber margins, where values fall below zero (Fig. $5)$.

The effect of increasing the magma chamber temperature from $300^{\circ} \mathrm{C}$ to $900{ }^{\circ} \mathrm{C}$ is most pronounced within two slightly stiffer layers (E1 and E3), and directly adjacent to the chamber in the right of 
the model. Firstly, the stiff layers concentrate larger values of both tensile and shear stress directly above the magma chambers when the temperature is increased. However, adjacent to the magma chamber walls the situation is more complex. The tensile stress instead decreases with increasing temperature but the shear stress increases with increasing temperature (Fig. 5a,b,c). The shear stress increase predominantly locates within the lower parts of the corresponding magma chambers (Fig. $5 \mathrm{e}, \mathrm{f}, \mathrm{g})$, and this accumulation of stress increases at deeper crustal levels coinciding with the thermal gradient applied (Fig. 5a-g).

Similar results are obtained in the three magma chamber configuration models (Figs. 6-8). In these cases the magnitude of tensile stresses around the larger deeper reservoir decreases from Figure 6 at the lowest temperatures tested to Figure 8 at the highest temperatures tested, whereas again the shear stress increases with temperature. It is further observed that the magntide of stresses are somewhat higher with the addition of the applied boundary loads (Fig 6-8). Also, increase in temperature promote an increase in $\sigma_{3}$ along some of the major modelled fault zones (Figure 6-8 $\mathrm{a}, \mathrm{b}, \mathrm{c}, \mathrm{d})$.

Due to the singularity in boundary conditions, in the vicinity of the lower corners of the domain, artificial stress concentrations are observed. These are artefacts that arise from the loading condition and not be evaluated in connection with the magmatic and faulted systems. We were careful to design the models such that the area of interest was sufficiently far from these artefact effects.

\section{Discussion and conclusions}

Although mechanical and thermomechanical interaction of magma chambers in the earth's crust have been previously investigated (Degruyter \& Huber, 2014; Degruyter et al., 2016; Towsend et 
al., 2019), the overall stress field generation around magma chambers were not documented.

Previously simulated thermomechanical simulations mainly explore heat transfer (e.g. Anne, 2009), cooling and longevity (e.g., de Silva \& Gregg, 2014; Gelman et al., 2013; Karakas et al., 2017), magma replenishment (Paterson et al., 2011; Hickey et al., 2016; Townsend et al., 2019) or level of stress relaxation (Grosfils, 2007; Karlstrom et al., 2010; Gerbault, 2012; Gudmundsson, 2012; Karaoğlu et al., 2016) from the magma chambers. Here, we present a suite of novel thermomechanical simulations which explore, for the first time, the stress and deformation field around magma chambers at different crustal depths formed both by tectonic and magmatic pressure and by thermo-elastic expansions.

In the suite of purely mechanical simulations, we demonstrated that the minimum principal compressive stress (tensile stress) is predominantly located at the lateral margins of the magma chambers and the magnitude of these stresses are always less than about $10 \mathrm{MPa}$ for the applied conditions. The distribution and level of von Mises shear stress are also less than $20 \mathrm{MPa}$ (Figure 4). These results are consistent with previously published data using purely elastic mechanical models (Thompson \& Connolly, 1995). When the results of purely mechanical and coupled thermomechanical simulations are investigated, it is possible to calculate the amounts of crustal deformation deriving from elastic thermal expansion. Coupled thermomechanical simulations show that the magnitude of Von Mises shear stress increased, when compared to the purely mechanical simulations, by around 1 order of magnitude to $200 \mathrm{MPa}$ (Figs. 5-8). This is in stark contrast to the level of minimum principal compressive stress which decreases substantially at the lateral edges of the magma chambers, with temperature. This indicates that the thermal expansion around magma chambers, over the range 300 to $1200{ }^{\circ} \mathrm{C}$ tested, can produce significant crustal thermal stresses and elastic deformation. We hence find that elastic thermal expansion induces two contrasting mechanical effects, i. it induces high levels of shear stress and ii. it suppresses tensile 
stresses generated through fluid overpressures. High levels of shear stress are generated as the overall stress field generated during thermal expansion is compressive, due in part to the expansion of the constituent grains in a rock mass (Browning \& Gudmundsson, 2015). Any tensile stresses generated by the opening pressure of a fluid (magma or water) are cancelled out by the expansion effect of the mineral grains. There may be situations where the competing forces act to combine and lower the stress level needed to fracture the host rock, but such interactions are beyond the scope of our models.

Throughout these numerical simulations, we use the inferred geological setting of a section of a complex crustal segment such as those found in Eastern Turkey (Karaoğlu et al., 2017), Galapagos (Searle \& Francheteau, 1986) and Chile (Gorring et al., 1997). Whilst the continuation of structures through the depth profile is likely an over-simplification, it allows an examination of the potential relationship between inferred crustal structures and thermomechanical loading. The thermomechanical relationship between the shallow magma chambers and the deeper magma reservoir that we infer to underlie a faulted caldera system located on the right-part on the model domain is highly sensitive to temperature increases which may encourage and facilitate magma transport between the two systems and to the surface (Figs. 6-8). However, it should be noted that our simulations do not consider phase changes or ductile deformation which are likely to be important processes at depths below $10 \mathrm{~km}$ and at the margins of hot magma chambers. Whilst we do not model such effects, it is possible that rocks around the magma chambers may act at least partially as visco-elastic and hence inhibit the development of crustal stresses or magmatic overpressures (de Silva \& Gregg, 2014; Degruyter et al., 2016). Further work is needed to consider the influence of such competing processes. It is clear though that the majority of the upper crust behaves as linear elastic (Grosfils et al., 2015) and hence simulations that determine the influence of temperature on elastic mechanical behaviour are important. 
374 Furthermore we do not directly consider magma chamber cooling but the longevity and cooling timescales of crustal magma chambers and reservoirs is a long debated topic in volcanology. Time sensitive numerical models (e.g., Annen, 2009; Gutiérrez \& Parada, 2010; Paterson et al., 2011;

377 Gelman et al., 2013; Degruyter and Huber, 2014; Karakas et al., 2017) and high-precision zircon geochronology from silicic plutons show that the longevity supported by $\mathrm{U}-\mathrm{Pb}$ geochronology for plutonic and volcanic systems (Costa et al., 2008; Schoene et al., 2012) is > 0.1 My for large silicic systems. In nature, any transfer of heat from a magma chamber or intrusion through the rocks will take time and hence the overall temperature field should be treated with caution. However, any thermal expansion or contraction will have a near instantaneous response in terms of the strain and stress produced. As such, the results presented here, are most likely appropriate and valid near the margins of the heated bodies. The models do not consider the transient analyses of cooling which occurs over tens to hundreds of thousands of years (Gelman et al., 2013; Degruyter \& Huber, 2014; Karakas et al., 2017) and has an effect on the distribution of thermo-mechanical stresses. Therefore, our models are likely most appropriate for considering the recent injection or replenishment of a et al., 2019). However, it is possible to approximate the host rock temperature field as a function of time using cooling models such as the conductive cooling model of Carslaw and Jaeger (1959) or any other appropriate model. For the size of shallow magma chambers presented in our study, they would take of the order of several tens to a hundred thousand years to cool from $900{ }^{\circ} \mathrm{C}$ to 300 ${ }^{\circ} \mathrm{C}$, if the effect of magma reinjection is neglected. As such, each temperature field and resultant stress field studied, can be linked in time with the inherent simplifications associated with any conductive cooling model (Carslaw and Jaeger, 1959). 
Our results elucidate a complex distribution of crustal stresses resulting from the arrangement of crustal structures, i.e., faults, layers and magma chambers (e.g., Karlstrom et al. 2010). In the purely mechanical simulations, both tensile and shear stresses concentrate predominantly around the

401

402

403

404

405

406

407

408

409

410

411

412

413

414

415

416

417

lateral margins of the magma chambers but also interact with the imposed caldera-faults around the caldera volcano in the east (Figure 4). The thermomechanical models show a substantially different distribution of stress with respect to the crustal faults. We find that many of the crustalscale faults (modelled as compliant units) change the distribution of crustal stresses in the thermomechanical simulations. In the threemagma-chamber model coupled thermomechanical simulations, the highest distribution of minimum principal compressive stress concentrates at around $10 \mathrm{~km}$ depth along the eastern part of one of the major faults (Figure 8a-c). The stress magnitude becomes more evident as the temperature applied for the deeper magma reservoir increases from $600{ }^{\circ} \mathrm{C}$ (Fig. 6), $900{ }^{\circ} \mathrm{C}$ (Fig. 7) to $1200{ }^{\circ} \mathrm{C}$ (Fig. 8). The simulation results of the two-magma-chamber models also demonstrate that the thermomechanical behaviour of different magmas with different temperatures may provide an opportunity to study coeval and monogenetic volcano feeder systems since these systems are linked to a volcanoes all round stress field (Figure 5). For example, lateral sill emplacement is expected throughout this crustal segment since the mechanical properties of the units vary substantially and likely encourage magma deflection (Figure 5-8) (Gudmundsson, 2011). We note a high concentration of tensile stress movement between the magma chambers in the east to a major fault zone in the west, especially when an extensional boundary loading condition was applied (Figure 5b), which may further encourage lateral magma or sill emplacement.

It should be noted that the effect of geothermal gradient applied in all simulations plays a significant role in stress distribution throughout the crust (Figs. 6-8). The expansion of rocks around the magma chambers and resulting crustal displacement applies a compressional load close to the chambers but a tensile load at suitably aligned crustal stress raisers. The effect in both cases sees a 
reduction in normal stress on the fault which may have implications for unloading the fault and promoting slip. However, the normal stress is also accompanied by counteractive shear stress towards the base of the fault zone which may further contribute to the stability of the fault. This indicates that there is a complex interplay between stress distributions resulting from thermal expansion in the crust.

The 2D, two-magma-chamber and three-magma-chamber models in this study, simulate the coupled stress and thermal effect on magma chambers in complex loading conditions such as those experienced in crustal segments in Eastern Turkey and can be used (with suitable modifications) to advance our understanding of magma storage, propagation and crustal deformation of crustal segments hosting magma worldwide.

\section{Acknowledgements}

This study was supported by funds from Eskisehir Osmangazi Üniversitesi (Project Numbers: 201715031, 201715A215, 2018-1995). Ö.K was supported by The Scientific and Technological Research Council of Turkey (TÜBİTAK) International Postdoctoral Research Fellowship Programme. J.B acknowledges support from Fondecyt award 11190143 and Fondap-Conicyt 15090013.

\section{Author Contributions}

Ö.K., Ö.B., M.B.T, J.B. performed the numerical modelling study and wrote the main manuscript text.

\section{Additional Information}


Supplementary information accompanies this paper

Competing interests: The authors declare no competing interests.References

Annen, C. (2009). From plutons to magma chambers: Thermal constraints on the accumulation of eruptible silicic magma in the upper crust. Earth and Planetary Science Letters, 284(3-4), 409416.

Aydin, I., Karat, H. I. \& Kocak, A. (2005). Curie Point Depth map of Turkey. Geophysical Journal International, 162, 633-640 (2005).

Bektaş, O., Ravat, D., Buyuksarac, A., Bilim, F. \& Ates, A. (2007). Regional geothermal characterization of East Anatolia from aeromagnetic, heat flow and gravity data. Pure and Applied Geophysics, 164, 975-998.

Browning, J. \& Gudmundsson, A. (2015). Caldera faults capture and deflect inclined sheets: an alternative mechanism of ring dike formation. Bulletin of Volcanology, 77(1), 4.

Browning, J., Meredith, P. \& Gudmundsson, A. (2016). Cooling-dominated cracking in thermally stressed volcanic rocks Geophysical Research Letters, 43(16), 8417-8425.

Burov, E. B. \& Guillou-Frottier, L. (1979). Thermomechanical behavior of large ash flow calderas. Journal of Geophysical Research: Solid Earth, 104(B10), 23081-23109.

Caricchi, L., Annen, C., Blundy, J., Simpson, G. \& Pinel, V. (2014). Frequency and magnitude of volcanic eruptions controlled by magma injection and buoyancy. Nature Geoscience, 7(2), 126130.

Carslaw, H.S. and Jaeger, J.C., 1959. Conduction of heat in solids. Oxford: Clarendon Press, 1959, 2nd ed.

Chestler, S. R. \& Grosfils, E. B. (2013). Using numerical modeling to explore the origin of intrusion patterns on Fernandina volcano, Galápagos Islands, Ecuador. Geophysical Research Letters, 40(17), 4565-4569.

Cloos, M. (1985). Thermal evolution of convergent plate margins: Thermal modeling and reevaluation of isotopic Ar-ages for blueschists in the Franciscan Complex of California. Tectonics, 4(5), 421-433.

Costa, F., Dohmen, R. \& Chakraborty, S. (2008). Time scales of magmatic processes from modeling the zoning patterns of crystals. Rev. Mineral. Geochem Reviews in Mineralogy and Geochemistry, 69(1), 545-594. 
de Silva, S. L. \& Gregg, P. M. (2014). Thermomechanical feedbacks in magmatic systems: Implications for growth, longevity, and evolution of large caldera-forming magma reservoirs and their supereruptions. Journal of Volcanology and Geothermal Research, 282, 77-91.

Deb, D. (2006). Finite Element Method, Concepts and Applications in Geomechanics. PHI Learning Private Limited, New Delhi.

Degruyter, W. \& Huber, C. (2014). A model for eruption frequency of upper crustal silicic magma chambers. Earth and Planetary Science Letters, 403, 117-130.

Degruyter, W., Huber, C., Bachmann, O., Cooper, K. M. \& Kent, A. J. (2016). Magma reservoir response to transient recharge events: The case of Santorini volcano (Greece). Geology, 44(1), $23-26$.

Dewey, J. F., Hempton, M. R., Kidd, W. S. F., Şaroğlu, F. \& Şengör, A. M. C. (1986). Shortening of continental lithosphere: the neotectonics of eastern Anatolia-a young collision zone in collision tectonics, edited by M. P. Coward and A. C. Ries. Geological Society, London, Special Publications, 19, 3-36.

Dufek, J. \& Bergantz, G. W. (2005). Lower crustal magma genesis and preservation: a stochastic framework for the evaluation of basalt-crust interaction. Journal of Petrology, 46, 2167-2195.

Eldursi, K., Branquet, Y., Guillou-Frottier, L. \& Marcoux, E. (2009). Numerical investigation of transient hydrothermal processes around intrusions: Heat-transfer and fluid-circulation controlled mineralization patterns. Earth and Planetary Science Letters, 288(1-2), 70-83.

Fitton, J. G., James, D. \& Leeman, W. P. (1991). Basic magmatism associated with late Cenozoic extension in the western United States - compositional variations in space and time. Journal of geophysical Research: Solid Earth, 96, 13693-13711.

Fredrich, J. T. \& Wong, T. F. (1986). Micromechanics of thermally induced cracking in three crustal rocks. Journal of Geophysical Research: Solid Earth, 91(B12), 12743-12764.

Gaffney, E. S., Damjanac, B. \& Valentine, G. A. (2007). Localization of volcanic activity, 2: effects of pre-existing structure. Earth and Planetary Science Letters, 263(3), 323-338.

Gelman, S. E., Gutiérrez, F. J. \& Bachmann, O. (2013). On the longevity of large upper crustal silicic magma reservoirs. Geology, 41(7), 759-762.

Gerbault, M. (2012). Pressure conditions for shear and tensile failure around a circular magma chamber, insight from elasto-plastic modelling. Geological Society, London, Special Publications, 367(1), 111-130.

Gerbault, M., Cappa, F. \& Hassani, R. (2012). Elasto-plastic and hydromechanical models of failure around an infinitely long magma chamber. Geochemistry, Geophysics, Geosystems, 13(3). 
Gorczyk, W., Willner, A. P., Gerya, T. V., Connolly, J. A., \& Burg, J. P. (2007). Physical controls of magmatic productivity at Pacific-type convergent margins: Numerical modelling. Physics of the Earth and Planetary Interiors, 163(1-4), 209-232.

Gorring, M. L., Kay, S. M., Zeitler, P. K., Ramos, V. A., Rubiolo, D., Fernandez, M. I. \& Panza, J. L. (1997). Neogene Patagonian plateau lavas: continental magmas associated with ridge collision at the Chile Triple Junction. Tectonics, 16(1), 1.

Grosfils, E. B. (2007). Magma reservoir failure on the terrestrial planets: Assessing the importance of gravitational loading in simple elastic models. Journal of Volcanology and Geothermal Research, 166(2), 47-75.

Grosfils, E. B., McGovern, P. J., Gregg, P. M., Galgana, G. A., Hurwitz, D. M., Long, S. M. \& Chestler, S. R. (2015). Elastic models of magma reservoir mechanics: a key tool for investigating planetary volcanism. Geological Society, London, Special Publications, 401(1), 239-267.

Gudmundsson, A. (2011). Rock Fractures in Geological Processes. Cambridge University Press, Cambridge.

Gudmundsson, A. (2012). Magma chambers: Formation, local stresses, excess pressures, and compartments. Journal of Volcanology and Geothermal Research, 237, 19-41.

Gutiérrez, F. \& Parada, M. A. (2010). Numerical modeling of time-dependent fluid dynamics and differentiation of a shallow basaltic magma chamber. Journal of Petrology, 51(3), 731-762.

Hickey, J., Gottsmann, J., Nakamichi, H. \& Iguchi, M. (2016). Thermomechanical controls on magma supply and volcanic deformation: application to Aira caldera, Japan. Scientific Reports 6, 32691.

Jaupart, C., Mareschal, J. C., Guillou-Frottier, L. \& Davaille, A. (1998). Heat flow and thickness of the lithosphere in the Canadian Shield. Journal of Geophysical Research: Solid Earth, 103(B7), 15269-15286.

Karakas, O. \& Dufek, J. (2015). Melt evolution and residence in extending crust: Thermal modeling of the crust and crustal magmas. Earth and Planetary Science Letters, 425, 131-144.

Karakas, O., Degruyter, W., Bachmann, O. \& Dufek, J. (2017). Lifetime and size of shallow magma bodies controlled by crustal-scale magmatism. Nature Geoscience, 10(6), 446.

Karaoğlu, Ö., Browning, J., Bazargan, M. \& Gudmundsson, A. (2016). Numerical modelling of triple-junction tectonics at Karlıova, Eastern Turkey, with implications for regional transport. Earth and Planetary Science Letters, 157-170. 
Karaoğlu, Ö., Selçuk, A. S. \& Gudmundsson, A. (2017). Tectonic controls on the Karlıva triple junction (Turkey): Implications for tectonic inversion and the initiation of volcanism. Tectonophysics, 694, 368-384.

Karaoğlu, Ö., Browning, J., Salah, M. K., Elshaafi, A. \& Gudmundsson, A. (2018). Depths of magma chambers at three volcanic provinces in the Karlıova region of Eastern Turkey. Bulletin of Volcanology, 80(9), 69.

Karaoğlu, Ö., Gülmez, F., Göçmengil, G., Lustrino, M., Di Giuseppe, P., Manetti, P., Savaşçın, M Y. \& Agostini, S. (2020). Petrological evolution of Karlıova-Varto volcanism (Eastern Turkey): Magma genesis in a transtensional triple-junction tectonic setting. Lithos, 364-365, 105524.

Karlstrom, L., Dufek, J. \& Manga, M. (2010). Magma chamber stability in arc and continental crust. Journal of Volcanology and Geothermal Research, 190, 249-270.

Lagabrielle, Y., Guivel, C., Maury, R. C., Bourgois, J., Fourcade, S., \& Martin, H. (2000). Magmatic-tectonic effects of high thermal regime at the site of active ridge subduction: the Chile Triple Junction model. Tectonophysics, 326(3-4), 255-268.

Le Corvec, N., Menand, T. \& Lindsay, J. (2013). Interaction of ascending magma with pre-existing crustal fractures in monogenetic basaltic volcanism: an experimental approach. Journal of Geophysical Research: Solid Earth, 118(3), 968-984.

Marsh, B. D. (1989). Magma chambers. Annual Review of Earth and Planetary Sciences, 17(1), $439-472$.

Mogi, K. (1958). Relations between eruptions of various volcanoes and the deformations of the ground surfaces around them. Bulletin of the Earthquake Research Institute, 36, 99-134.

Parks, M. M., Moore, J. D., Papanikolaou, X., Biggs, J., Mather, T. A., Pyle, D. M., Raptakis, C., Paradissis, D., Hooper, A., Parsons, B. \& Nomikou, P. (2015). From quiescence to unrest: 20 years of satellite geodetic measurements at Santorini volcano, Greece. Journal of Geophysical Research: Solid Earth, 120(2), 1309-1328.

Parmigiani, A., Degruyter, W., Leclaire, S., Huber, C. and Bachmann, O., 2017. The mechanics of shallow magma reservoir outgassing. Geochemistry, Geophysics, Geosystems, 18(8), pp.28872905.

Paterson, S. R., Okaya, D., Memeti, V., Economos, R. \& Miller, R. B. (2011). Magma addition and flux calculations of incrementally constructed magma chambers in continental margin arcs: combined field, geochronologic, and thermal modeling studies. Geosphere, 7, 1439-1468.

Pearce, J. A., Bender, J. F., DeLong, S. E., Kidd, W. S. F., Low, P. J., Güner, Y., Şaroğlu, F., Yilmaz, Y., Moorbath, S. \& Mitchell, J. G. (1990). Genesis of collision volcanism in Eastern Anatolia, Turkey. Journal of Volcanology and Geothermal Research, 44, 189-229. 
Schoene, B., Schaltegger, U., Brack, P., Latkoczy, C., Stracke, A. \& Günther, D. (2012). Rates of magma differentiation and emplacement in a ballooning pluton recorded by $\mathrm{U}-\mathrm{Pb}$ TIMS-TEA, Adamello batholith, Italy. Earth and Planetary Science Letters, 355, 162-173.

Searle, R. C. \& Francheteau, J. (1986). Morphology and tectonics of the Galapagos triple junction. Marine Geophysical Researches, 8(2), 95-129.

Smith, D. L. \& Evans, B. (1984). Diffusional crack healing in quartz Journal of Geophysical Research: Solid Earth, 89 (B6), 4125-4135.

Şengör, A.M.C. (2014). Triple junction. Encyclopedia of Marine Geosciences: pp. 1-13. http://dx.doi.org/10.1007/978-94-007-6644-0_122-1

Şengör, A. M. C., Görür, N. \& Şaroğlu, F. (1985). Strike-slip faulting and related basin formation in zones of tectonic escape: Turkey as a case study. Strike Slip Faulting and Basin Formation. In: Biddle, K. T, Christie-Blick, N. (Eds.). Society of Economical Paleontologists and Mineralogists, Special Publication, 37, 227-267.

Tabatabaian, M. (2014). COMSOL for Engineers. Mercury Learning and Information, Boston, USA.

Thompson, A. B. \& Connolly, J. A. (1995). Melting of the continental crust: some thermal and petrological constraints on anatexis in continental collision zones and other tectonic settings. Journal of Geophysical Research: Solid Earth, 100(B8), 15565-15579.

Topuz, G., Candan, O., Zack, T. \& Y1lmaz, A. (2017). East Anatolian plateau constructed over a continental basement: No evidence for the East Anatolian accretionary complex. Geology 45 (9), 791-794.

Townsend, M., Huber, C., Degruyter, W. \& Bachmann, O. (2019). Magma Chamber Growth During Intercaldera Periods: Insights From Thermo-Mechanical Modeling With Applications to Laguna del Maule, Campi Flegrei, Santorini, and Aso. Geochemistry, Geophysics, Geosystems, 20(3), 1574-1591. 
613

614

615

616

617

618

619

620

621

622

623 